\title{
KONSEP PENDIDIKAN KARAKTER MENURUT IMAM AL-HADDAD DAN RELEVANSINYA DENGAN PENDIDIKAN KARAKTER DI INDONESIA
}

\author{
Mitsalina Nadhil Harani ${ }^{1}$, Ela Sholihah ${ }^{2}$, Dewi Indrawati ${ }^{3}$ \\ 123 Sekolah Tinggi Fatahillah Serpong; Indonesia \\ nadhilharani97@gmail.com
}

\begin{abstract}
Abstrak: The community needs special attention to improve in a better direction; significant efforts are required. The built actions are a form of improvement efforts to various problems in the world of education. Character building is seen as a solution to these problems. This study aims to describe conceptually Islamic character building in the millennial era. This study uses a descriptive qualitative approach. This type of research is library research (library research). The subject of this research is the thought of Imam AlHaddad. The study results suggest that character building, according to Imam Al-Haddad, is a perspective through the approach of tasawuf moral. Sufism is a teaching that has developed since classical and modern in countries with the Syafi'i school of thought. Sufism moral orientation leads to comprehensive character improvement based on the Al-Qur'an and hadith. In Sufism, it contains the morals of students to Allah SWT, the morals of students to teachers, the morals of students to themselves, and the morals of students to fellow humans. According to Imam Al-Haddad, the conception of character building is related to the values of character building. This linkage will strengthen the character values themselves, which students easily apply in studying or in their daily lives.
\end{abstract}

Keywords: Character building; Imam Al-Haddad; Sufism morals.

\section{PENDAHULUAN}

Pada era globalisasi yang semakin pesat perkembangannya melalui teknologi informasi membuat semua hal menjadi dekat sekaligus mudah mencapainya. Bagi para peserta didik, kecanggihan teknologi informasi dapat menjadi dampak positif. Dengan adanya teknologi informasi dapat memudahkan peserta didik mengerjakan tugas atau menambah pengetahuan secara luas. Hal ini dapat mendukungnya dalam proses belajar dengan hasil yang maksimal. Akan tetapi, di sisi lain terdapat dampak negatif untuk peserta didik, jika penggunaan teknologi tersebut tidak terkontrol dengan baik, maka akan menanamkan karakter negatif yang dapat menghambat perkembangan karakter di manapun mereka berada.

Di sisi lain, menurut website CNN Indonesia dunia pendidikan telah mengalami kemerosotan yang mengakibatkan kenakalan terhadap peserta didik, seperti: narkotika, free sex, tawuran antar pelajar, kasus bullying, pencurian, dan balapan liar. Survei dari Badan Narkotika Nasional (BNN) dan Lembaga Ilmu Pengetahuan Indonesia (LIPI) menunjukkan 2,3 juta pelajar atau mahasiswa di Indonesia pernah mengonsumsi narkotika. Angka itu setara dengan 3,2 persen dari populasi kelompok tersebut. Hasil survei tersebut dapat menggambarkan berbagai perilaku kenakalan lainnya yang memungkinkan meningkat pada setiap tahunnya.

Penelitian lain yang sebelumnya telah di lakukan untuk menggali pendidikan karakter menurut Imam Al-Haddad dapat di lihat berikut ini. 
Tabel 1. Penelitian Terdahulu

\begin{tabular}{|c|c|c|}
\hline No. & Judul Penelitian & Distingsi \\
\hline 1. & $\begin{array}{l}\text { Pendidikan Dalam Islam Pemikiran al- } \\
\text { Ghazali tentang Pendidikan Karakter } \\
\text { Anak Berbasis Akhlak al-Karimah. } \\
\text { Syamsul Kurniawan. } 2017\end{array}$ & \begin{tabular}{lrr} 
Penelitian & \multicolumn{2}{r}{ Syamsul } \\
mengutamakan pendidikan & \multicolumn{2}{r}{ karakter } \\
berbasis akhlak karimah. Di dalam \\
penelitian ini menggunakan kitab Ayyuhal \\
Walad, karya Imam al-Ghazali sebagai \\
acuan pendidikan spiritual untuk \\
mengembangkan karakter anak.
\end{tabular} \\
\hline 2. & $\begin{array}{l}\text { Pendidikan Karakter Menurut KH. Hasyim } \\
\text { Asy'ari (Perspektif } \quad \text { Filosofis). Amin } \\
\text { Nurbaedi. } 2018\end{array}$ & $\begin{array}{l}\text { Amin Nurbaedi mengulas pendidikan } \\
\text { karakter dalam tinjauan filosofis menurut } \\
\text { KH. Hasyim Asy'ari. Di dalam penelitian ini } \\
\text { menyatukan perbuatan hati dalam } \\
\text { mengaplikasikan upaya menuntut ilmu. }\end{array}$ \\
\hline 3. & $\begin{array}{l}\text { Peran Pondok Pesantren dalam } \\
\text { Membentuk Karakter Bangsa Santri di Era } \\
\text { Disrupsi. Pasmah Chandra. } 2020\end{array}$ & $\begin{array}{l}\text { Pasmah Chandra mengungkapkan peran } \\
\text { pondok pesantren dalam membentuk } \\
\text { karakter manusia secara komprehensif dan } \\
\text { aktual. Penelitian ini menunjukkan bahwa } \\
\text { pondok pesantren adalah lembaga } \\
\text { pendidikan Islam yang paling efektif di era } \\
\text { disrupsi. }\end{array}$ \\
\hline
\end{tabular}

Pada abad ke 12 Hijriyyah seorang ulama mujtahid, beliau merupakan bagian dari golongan Sâdah 'Alawiyyîn. Mereka para Sâdah 'Alawiyyîn mendidik orang yang mencari ilmu dengan akhlak mulia, bersungguh-sungguh dalam mendidik sehingga semua tindak tanduknya sama seperti pribadi mulia Nabi Muhammad SAW (al-Badawi, 2016). Imam Al-Haddad memberikan kepeduliannya berupa nasehat-nasehat kepada peserta didik pada masanya untuk membangun pendidikan karakter dalam ruang lingkup akhlak tasawuf.

Berdasarkan penguraian di atas, dapat di ketahui konsep pendidikan karakter yang di kemukakan oleh Imam Al-Haddad penting untuk dipelajari, terlebih untuk para peserta didik yang berada dalam pendidikan formal, informal, nonformal, dan tenaga pendidik. Dengan memahami konsep pendidikan karakter menurut Imam Al-Haddad dan relevansinya dengan pendidikan karakter di Indonesia dapat menunjukkan bahwa pembelajaran dari ulama terdahulu melalui karyanya memberikan konstribusi yang efektif untuk menyelesaikan permasalahan dalam dunia pendidikan di era globalisasi.

\section{METODE}

Untuk memahami permasalahan, penelitian ini menggunakan pendekatan kualitatif deskriptif. Penelitian dengan menggunakan pendekatan kualitatif deskriptif digunakan untuk menyajikan data berdasarkan kejadian atau fakta, keadaan, fenomena, dan variabel dalam bentuk bukti konkret (Saefudin Azwar, 2001). Selanjutnya, jenis penelitian ini yaitu penelitian kepustakaan (library research) artinya sebuah studi dengan mengkaji buku-buku, naskah-naskah, atau majalah-majalah yang bersumber dari khazanah kepustakaan yang relevan dengan 
Scaffolding: Jurnal Pendidikan Islam dan Multikulturalisme Vo. 3, No. 2, Juli-Desember 2021: 123-134

permasalahan yang diangkat dalam penelitian. Semua sumber berasal dari bahan-bahan tertulis berkaitan dengan permasalahan penelitian dan dokumenter literatur lainnya (Hadi, 1980). Data primer dalam penelitian ini menggunakan karya-karya Imam Al-Haddad. Adapun data sekunder dalam penelitian ini menggunakan semua literatur berupa buku dan artikel dari tokoh lainnya yang memiliki persamaan tentang pendidikan karakter menurut Imam Al-Haddad.

\section{HASIL DAN PEMBAHASAN}

\section{Pendidikan Karakter}

Kata "character" berasal dari bahasa Yunani charassein, yang berarti to engrave (melukis, menggambar), seperti orang yang melukis kertas, memahat batu atau metal. Berakar dari pengertian yang seperti itu, character kemudian diartikan sebagai tanda atau ciri khusus. Dalam kamus terbaru Bahasa Indonesia, karakter artinya sifat, akhlak, budi pekerti yang menjadi ciri khas seseorang. I.R Pedjawawijatna mengemukakan: “Watak atau karakter ialah seluruh aku yang ternyata dalam tindakannya (insani, jadi dengan pilihan) terlibat dalam situasi, jadi memang di bawah pengaruh dari pihak bakat, temperamen, keadaan tubuh, dan lain sebagainya" (Evinna Cinda Hendriana \& Arnold Jacobus, 2016).

Menurut Thomas Lickona, pendidikan karakter adalah pendidikan untuk membentuk kepribadian seseorang melalui pendidikan budi pekerti, yang hasilnya terlihat dalam tindakan nyata seseorang, yaitu tingkah laku yang baik, jujur, bertanggungjawab, menghormati hak orang lain, kerja keras, dan sebagainya (Hambali, 2008).

Dari pendapat yang di kemukakan oleh para ahli dapat disimpulkan bahwa pendidikan karakter adalah upaya sadar seseorang untuk memasukkan nilai-nilai perilaku manusia yang dapat mempengaruhi sikap, perbuatan, perkataan, dan perilaku seseorang kepada Tuhan, diri sendiri, dan sesama manusia. Pendidikan karakter dapat mewujudkan sumber daya manusia yang mempunyai nilai guna dan berakhlak mulia.

\section{Melacak jejak Imam Al-Haddad pada masanya}

Imam Al-Haddad dilahirkan di kota Tarim pada malam Senin, tanggal 5 Shafar, tahun 1044 H. Ketika umur 4 tahun, beliau tertimpa penyakit cacar yang menyebabkan tidak bisa melihat (Al-Badawi, 2016). Hal ini tidak membuatnya patah semangat dalam mencari ilmu-ilmu yang dipelajari dalam agama Islam dan mampu membuatnya dekat kepada Allah SWT. Beliau bersungguh-sunguh menghafal Al-Qur'an hingga selesai. Beliau sangat bersyukur kepada Allah SWT, ridha dengan apa yang Allah SWT tetapkan untuknya, dan beramal untuk mencari keridhaan Allah SWT.

Beliau berasal dari kota Tarim di Hadramaut Yaman. Di masanya beliau adalah yang paling faqîh (ahli dalam ilmu fiqh) dan bermadzhab Syafi'i. Beliau juga merupakan ulama 
Scaffolding: Jurnal Pendidikan Islam dan Multikulturalisme Vo. 3, No. 2, Juli-Desember 2021: 123-134

terunggul yang berakidah ahlussunnah yang berjalan diatas faham asy'ariy dan terdepan dalam jalan hidup dan pendidikan pada jalan para sufi. Julukannya adalah "guru besar Islam" dan "poros dakwah dan petunjuk". Beliau adalah seorang pembaharu dalam tarekat para Sâdah Bani 'Alawi. Nasab beliau sampai kepada Al-Imam Husin bin Ali Abu Thâlib anak Fathimah binti Rasulullah SAW (Al-Haddad, 2017). Sosok Imam Al-Haddad telah mencapai kesempurnaan ilmu, akal, hikmah dan kuatnya hafalan yang membuat Imam Al-Haddad unggul hingga zaman modern. Ilmu yang di sampaikannya terperinci dan lengkap keterangannya sehingga orang-orang yang menimba ilmu darinya juga mendapatkan banyak nilai guna.

\section{Karakteristik Pendidikan Karakter menurut Imam Al-Haddad}

Menurut al-Attas, mengungkapkan bahwa pendidikan adalah pengenalan dan pengakuan mengenai suatu tempat sesuai dengan tatanan penciptaan yang ditanamkan secara progresi ke dalam diri manusia, proses ganda, pertama melibatkan masuknya unit-unit makna suatu objek pengetahuan ke dalam jiwa seseorang dan yang kedua melibatkan sampainya jiwa pada unit-unit makna tersebut (Daud, 2003).

Pendidikan yang telah ada dalam diri manusia selanjutnya dilatih dalam unit-unit makna secara komprehensif. Secara umum konsepsi yang telah dibangun oleh Imam Al-Haddad sudah dijalankan oleh para sufi dalam ruang lingkup akhlak tasawuf. Dalam berbagai pemikiran Imam Al-Haddad menjadi suatu solusi untuk menyelesaikan semua permasalahan dalam pendidikan karakter.

Pendidikan karakter menurut Imam Al-Haddad secara terperinci dapat diklasifikasikan menjadi: jujur dalam niat mencari ilmu, bersikap sabar, bersikap tawaduk/rendah hati, mengamalkan ilmu, akhlak peserta didik kepada guru, menjaga kebersihan dan mencari rezeki yang halal. Menurut hemat penulis, konsepsi pendidikan karakter yang digunakan oleh Imam AlHaddad untuk perbaikan karakter dengan memerhatikan urgensi akhlak secara komprehensif.

Penulis akan menguraikan mengenai konsepsi pendidikan karakter menurut Imam AlHaddad sebagai berikut:

a. Jujur dalam niat mencari ilmu

Di dalam kitab Risâlah Âdâb Sulûk al-Murîd, Imam Al-Haddad memberikan keterangan mengenai hadis Nabi Muhammad SAW berkaitan dengan niat sebagai berikut:

Beliau Rasulullah SAW telah memberitakan bahwasanya tidak ada amal kecuali dengan niat, dan sesungguhnya manusia diberi pahala dan dibalas sesuai dengan niatnya. Jika niatnya baik, maka ia akan dibalas dengan kebaikan. Jika niatnya jelek, maka ia akan dibalas dengan kejelekan. Barangsiapa yang baik niatnya, maka pasti baik pula perbuatannya tak diragukan lagi. Barangsiapa yang jelek niatnya, pasti jelek pula amalnya tak diragukan lagi, walaupun dalam bentuk gambaran 
kebaikan. Seperti seorang yang berbuat baik karena mengharapkan penilaian dari makhluk (Al-Haddad, 2017).

Imam Al-Haddad menjelaskan bahwa langkah pertama yang diperhatikan oleh peserta didik adalah jujur dalam niat. Dalam kejujuran niat terdapat kejujuran dalam beramal. Niat mencari ilmu karena Allah SWT dan untuk menghidupkan syari'at Nabi Muhammad SAW, maka niat yang seperti ini akan mendukungnya dalam beramal. Oleh karena itu, sudah seharusnya peserta didik sebelum menuntut ilmu mempunyai niat yang dapat mengantarkannya kepada amal-amal yang baik untuk mencapai keberhasilan belajar.

b. Bersikap sabar

Imam Al-Haddad menyampaikan dalam pasal tingkatan nafsu dan sabar sebagai berikut:

Barangsiapa yang mau mendapatkan semua kebajikan dan beruntung serta terlaksana segenap cita-citanya, sudah selayaknya ia bersabar di setiap keadaan. (Al-Haddad, 2017).

Imam Al-Haddad menyampaikan segala kondisi dengan kesabaran yang baik akan membuahkan kebaikan. Sabar merupakan salah satu karakter yang harus terus dilatih terus menerus oleh peserta didik. Dalam sikap sabar terdapat pengendalian diri yang memiliki nilai di atas rata-rata tabiat manusia pada umumnya dan mampu memantulkan kekuatan jiwa seseorang dalam menghadapi permasalahan hidupnya. Dengan membiasakan bersikap sabar membuat peserta didik lebih selektif mengambil tindakan yang dapat dipertanggungjawabkan.

c. Bersikap tawaduk/rendah hati

Tawaduk adalah sikap rendah hati yang melahirkan kelembutan hati tanpa merendahkan diri. Dalam hal ini seseorang bersikap sesuai dengan wewenangnya dengan tidak otoriter dan menurunkan kadar dalam dirinya. Serta dengan sebab menginginkan kemuliaan tetap dalam kemuliaan dan kedudukannya. Sebagai peserta didik untuk mendapatkan kesuksesan dalam mencapai cita-citanya, ia harus memiliki sikap tawaduk/rendah hati. Kesuksesan yang di raih dengan sikap rendah hati mampu membuka jalan kesuksesan selanjutnya. Karena rendah hati merupakan salah satu sikap seorang pemimpin dan peserta didik harus mampu memimpin dirinya sendiri.

Imam Al-Haddad menjelaskan karakter yang harus ada pada seorang peserta didik yaitu tawaduk/rendah hati.

Murid adalah mereka yang tidak diperbudak oleh tipu daya, tidak diperhamba oleh sifat ego, tidak dikalahkan oleh syahwat, dan tidak dikuasai oleh kebiasaan. Bicaranya dzikir dan hikmah. Diamnya adalah bertafakkur dan mengambil pelajaran. Amalnya mendahului ucapannya dan perbuatannya membenarkan 
ilmunya. Tanda-tandanya adalah khusyu' dan tenang selimutnya adalah rendah hati dan patah hati karena Allah (Al-Haddad 2017).

Sebagai seorang peserta didik harus memiliki karakter tawaduk/rendah hati. Rendah hati menurut Imam Al-Haddad adalah peserta didik yang tidak membanggakan diri, tidak merendahkan sesama manusia, dan dapat menundukkan egoisme dalam dirinya. Sikap seperti ini di butuhkan oleh peserta didik dalam mencari ilmu ataupun berinteraksi dengan siapapun dalam kehidupan sehari-hari. Tentunya sikap tawaduk akan sangat berpengaruh dalam diri peserta didik, jika di iringi dengan sikap ramah terhadap siapapun.

d. Mengamalkan ilmu

Dalam tafsir Jalalain, menjelaskan bahwa orang yang hanya pandai berkata-kata tetapi tidak mengamalkan terhadap apa yang telah diucapkannya seperti tuntunan untuk berjihad (berperang) di jalan Allah SWT. Tetapi mereka berpaling dan melarikan diri setelah perintah datang, maka kemurkaan Allah yang amat besar baginya, karena menyesuaikan antara ucapan dengan perbuatan disebut dengan akhlak yang mulia, yang dalam hal ini tentunya menyebarluaskan ajaran-ajaran Islam tersebut (al-Mahally, 1923)

Imam Al-Haddad menjelaskan mengenai pentingnya peserta didik dalam mengamalkan ilmu yang telah diraihnya sebagai berikut:

Selayaknya seseorang yang sudah mempelajari suatu ilmu namun tidak di amalkan, sama saja dengan orang yang tidak pernah belajar padahal ia mempunyai kemampuan untuk mengamalkan ilmu, kecuali karena ia di azab oleh Allah sudah sangat memberikan kebenaran yang sesungguhnya. Dengan keadaan yang semacam itu, orang yang tidak pernah belajar lebih baik daripada ia. Oleh karena itu, ada yang mengatakan bahwa setiap ilmu yang tidak berguna bagimu, maka kebodohan lebih berguna bagimu daripadanya. (Al-Haddad, 2017).

Dalam kitabnya Imam Al-Haddad menjelaskan untuk orang yang tidak mengamalkan ilmunya sama dengan orang yang tidak pernah belajar. Melalui nasihat di atas perlu di renungkan oleh peserta didik. Nampak Imam Al-Haddad menganjurkan peserta didik untuk mengamalkan ilmu. Ilmu yang bermanfaat adalah ilmu yang di amalkan sesuai tuntunannya. Mengamalkan ilmu termasuk karakter peserta didik yang harus diaplikasikan guna memperkuat ingatan dalam pelajaran dan membuka peluang diri untuk berkontribusi dalam keilmuan.

e. Akhlak peserta didik kepada guru

Sayyidina 'Ali karramallâhu wajhah pernah berkata, "Aku adalah budak dari orang yang telah mengajariku satu huruf. Jika mau ia boleh menjualnya, boleh pula membebaskannya dan jika minat ia pun boleh memperbudaknya." (Baradja, 1993). Salah satu akhlak peserta didik kepada gurunya adalah bertanya tentang sesuatu yang belum ia 
Scaffolding: Jurnal Pendidikan Islam dan Multikulturalisme Vo. 3, No. 2, Juli-Desember 2021: 123-134

ketahui dengan penuh akhlak yang mulia. Sebagaimana nasehat Imam Al-Haddad sebagai berikut:

Wahai para murid, jika engkau menginginkan sesuatu dari syaikhmu atau akan bertanya tentang sesuatu kepadanya janganlah kewibawaannya dan adabmu bersamanya menghalangimu dari meminta atau bertanya kepadanya. Bertanyalah kepadanya satu kali, dua kali, dan tiga kali. Berdiam dari permintaan dan pertanyaan bukan termasuk adab yang baik. Kecuali jika syaikhmu mengisyaratkanmu untuk berdiam dan memerintahkanmu untuk menginggalkan pertanyaan. Dalam hal ini haruslah kau mematuhinya.

Menurut Imam Al-Haddad akhlak peserta didik kepada guru merupakan salah satu pendidikan karakter. Peserta didik mendengarkan pelajaran yang guru sampaikan dengan penuh perhatian. Akhlak peserta didik kepada gurunya meliputi melakukan sesuatu yang diperintahkan dan menjauhi segala sesuatu yang dilarang oleh gurunya atas dasar ketaatan kepada Allah SWT. Ilmu yang disertai dengan akhlak mulia akan menghasilkan ilmu yang bermanfaat di kemudian hari. Oleh karena itu, sangat penting peserta didik untuk memperhatikan akhlaknya dihadapan gurunya.

f. Menjaga kebersihan

Allah SWT befirman dalam Al-Qur'an sebagai berikut:

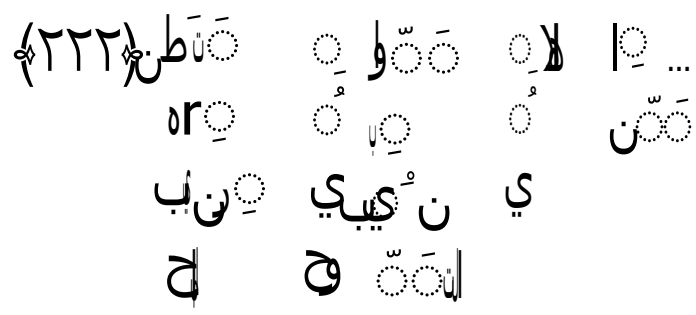

Sesungguhnya Allah menyukai orang-orang yang bertobat dan menyukai orangorang yang menyucikan diri. (Al-Baqarah/2: 222)

Al-Qur'an sebagai pedoman hidup umat Islam menggambarkan bahwa orang beriman kepada Allah adalah orang yang senantiasa menjaga kebersihan dirinya. Sebagaimana diisyaratkan pada ayat di atas dengan berpasangan bersama orang-orang yang bertaubat dan membersihkan diri, selayaknya bagi seorang muslim membersihkan diri menjadi esensial perilaku dan sama tingkatannya dengan esensial taubat kepada Allah SWT. Orang yang selalu membersihkan diri akan mendapat cinta dari Allah SWT seperti Allah SWT mencintai orang yang selalu bertaubat. Nabi Muhammad SAW juga menyatakan bahwa at-tahûru shatru al-îmân sebagai landasan utama dalam agama Islam dalam budaya hidup bersih (al-Baihaqi, 1995).

Dalam nasehat Imam Al-Haddad menjelaskan sebagai berikut:

Hendaklah setiap murid selalu dalam keadaan suci. (Habib Abdullah bin Alwi Al- 
Scaffolding: Jurnal Pendidikan Islam dan Multikulturalisme

Vo. 3, No. 2, Juli-Desember 2021: 123-134

Haddad, 2017: 50-51). 
Scaffolding: Jurnal Pendidikan Islam dan Multikulturalisme Vo. 3, No. 2, Juli-Desember 2021: 123-134

Betapa sangat dianjurkan untuk para peserta didik di manapun ia berada agar selalu merawat diri dari kebersihan badan, tempat, ataupun lingkungan. Nur Cholis Majid menyatakan bahwa karena jiwa manusia berasal dari penciptanya, maka esensinya setiap jiwa manusia adalah makhluk yang mempunyai kesucian, kebaikan, dan kebenaran meskipun bisa tidak terbukti keseluruhannya (Taher, 2013). Maka hendaknya peserta didik untuk selalu menjaga kebersihan pakaian, badan, dan tempat dimanapun ia berada. Menjaga kebersihan adalah salah satu upaya agar dapat di cintai oleh Allah SWT.

Kebersihan merupakan sebagian dari iman, maka hendaknya peserta didik untuk selalu menjaga kebersihan di manapun ia berada. Seperti membuang sampah pada tempatnya, membersihkan tempat yang kotor merupakan upaya menjaga kebersihan agar terhindar dari macam penyakit. Dengan menjaga kebersihan, peserta didik akan lebih konsentrasi dalam proses belajarnya. Hal ini dapat mendukung peserta didik lebih mudah memahami pelajaran yang disampaikan oleh guru.

g. Mencari rezeki yang halal

Pengertian kata rezeki mempunyai makna secara bahasa dan istilah yang tidak dapat dipisahkan, secara bahasa makna rezeki diartikan sebagai pemberian, yaitu ada orang yang di beri sesuatu padanya, dan ada sesuatu yang mempunyai nilai manfaat untuk makhluk ciptaan-Nya. Selanjutnya, istilah rezeki bagi manusia juga sesuatu yang bernilai manfaat meliputi kebaikan dunia dan akhirat. Yang menjamin rezeki yaitu Allah SWT, Allah SWT mengatur setiap rezeki makhluk-Nya. Walaupun demikian seseorang tidak boleh malas dan tidak mencari rezeki, karena dengan ikhtiar memperoleh rezeki di dunia dapat menjadi sebab-sebab terbukanya rezeki seorang hamba (Pasmadi, 2015).

Sebagaimana nasehat Imam Al-Haddad mengenai mencari rezeki yang halal sebagai berikut:

Allah SWT berfirman, "Maka mintalah rezeki itu di sisi Allah, dan sembahlah Dia dan bersyukurlah kepada-Nya." (QS. al-Ankabut [29]: 17) Apakah kau tidak melihat bahwa Dia yang Maha Suci memberi rezeki kepada orang-orang kafir yang menyembah kepada selain-Nya? Apakah menurut pendapatmu Dia tidak akan memberikan rezeki-Nya kepada orang-orang beriman yang tidak menyembah selain Dia? Dia memberi rezeki kepada orang-orang yang bermaksiat kepada-Nya dan melanggar perintah-Nya. Apakah Dia tidak akan memberi rezeki kepada orangorang yang taat kepada-Nya, memperbanyak zikir dan syukur kepada-Nya?

Yang perlu kamu ketahui, bahwa ketika kita bergerak mencari rezeki selama apa yang kita cari sesuai dengan syari'at tidak ada masalah mau mencari rezeki di manapun. Akan tetapi, mengenai persoalan rezeki dapat menjadi suatu permasalahan dan dosa jika hati tidak dapat tenang, pikiran, kesenangan, kegelisahnnya tertuju kepada rezeki yang sudah di atur oleh Allah SWT. (Al-Haddad, 2017). 
Allah berfirman agar hamba-Nya meminta rezeki di sisi-Nya. Rezeki itu terbagi untuk semua orang termasuk yang orang yang beriman, orang yang bermaksiat, dan orang-orang kafir. Mencari rezeki yang halal merupakan karakter peserta didik. Dengan rezeki yang halal akan membawa peserta didik lebih tenang dalam mencari ilmu. Tentunya hal ini akan membuat peserta didik dapat berhasil dalam mencari ilmu yang bermanfaat dunia akhirat. Rezeki yang halal akan membawanya kepada keterbukaan pintu rezeki lainnya.

\section{Relevansi Nilai-Nilai Karakter menurut Pusat Kurikulum Depdiknas dengan Pendidikan Karakter menurut Imam Al-Haddad}

Sosok ulama pewaris Nabi Muhammad SAW seperti Imam Al-Haddad merupakan seorang pendidik yang unggul pada masanya. Berbagai karya-karyanya telah tersebar ke pelosok negeri. Dalam karya-karyanya terdapat banyak keistimewaan yang telah menarik banyak kalangan dalam dunia pendidikan Islam sebagai acuan dalam mendidik dengan kesungguhan.

Karakter yang diusung oleh Imam Al-Haddad dapat menjadi solusi atas semua permasalahan karakter pada era globalisasi. Karakter seperti ini menjadi suatu karakter Islami yang merupakan identitas luhur peserta didik. Sebab semua nasehat Imam Al-Haddad merupakan nasehat-nasehat yang menunjukkan kejeniusannya dan bukti atas kekuasaan Allah SWT. Hal ini menjadi suatu kejayaan yang perlu untuk dipertahankan dari zaman ke zaman.

Untuk lebih menguatkan pelaksanaan pendidikan karakter pada satuan pendidikan, Pusat Kurikulum Depdiknas mengusung 18 nilai karakter yang akan memberikan nilai guna. Semua karakter bersumber dari norma agama, Pancasila, budaya, dan tujuan pendidikan nasional, yaitu: (1) Religius, (2) Jujur, (3) Toleransi, (4) Displin, (5) Kerja keras, (6) Kreatif, (7) Mandiri, (8) Demokratis, (9) Rasa Ingin Tahu, (10) Semangat Kebangsaan, (11) Cinta Tanah Air, (12) Menghargai prestasi, (13) Bersahabat/komunikatif, (14) Cinta Damai, (15) Gemar Membaca, (16) Peduli Lingkungan, (17) Peduli Sosial, (18) Tanggung Jawab (Pusat Kurikulum Depdiknas, 2010).

Oleh karena itu, mengacu pada nilai-nilai karakter di atas, berikut ini akan dijabarkan relevansi nilai-nilai karakter dengan konsepsi pendidikan karakter Imam Al-Haddad. Untuk lebih mempermudah penulis mencantumkan relevansi sesuai dengan substansi isinya.

Tabel 2. Relevansi Nilai Karakter Menurut Pusat Kurikulum Depdiknas dan Konsepsi Pendidikan Karakter Imam Al-Haddad

\begin{tabular}{lll}
\hline No. & \multicolumn{1}{|c}{$\begin{array}{c}\text { Nilai-Nilai Pendidikan } \\
\text { Karakter Menurut Pusat } \\
\text { Kurikulum Depdiknas }\end{array}$} & $\begin{array}{c}\text { Pendidikan Karakter menurut Imam Al- } \\
\text { Haddad }\end{array}$ \\
\hline 1. & Nilai Religius & Bersikap bersabar dan rendah hati \\
\hline 2. & Nilai Jujur & Jujur dalam niat mencari ilmu \\
\hline
\end{tabular}




\begin{tabular}{|c|c|c|}
\hline 3. & Nilai Displin & $\begin{array}{l}\text { Displin dalam waktu ibadah, mencari ilmu, mencari } \\
\text { rezeki, dll. }\end{array}$ \\
\hline 4. & Nilai Kerja Keras & $\begin{array}{l}\text { Kerja keras melawan rasa malas dari ketaatan } \\
\text { kepada Allah SWT }\end{array}$ \\
\hline 5. & Nilai Mandiri & $\begin{array}{l}\text { Tidak diperhamba oleh sifat ego, syahwat, dan tidak } \\
\text { dikuasai oleh kebiasaan }\end{array}$ \\
\hline 6. & Nilai Rasa Ingin Tahu & $\begin{array}{l}\text { Bertanya tentang sesuatu kepada gurunya satu kali, } \\
\text { dua kali dan tiga kali. }\end{array}$ \\
\hline 7. & $\begin{array}{l}\text { Nilai Semangat Kebangsaan dan } \\
\text { Nasionalisme }\end{array}$ & $\begin{array}{l}\text { Semangat mendekatkan diri kepada Allah SWT dan } \\
\text { tidak mengulang dosa. }\end{array}$ \\
\hline 8. & $\begin{array}{l}\text { Nilai Komunikatif dan } \\
\text { Bersahabat }\end{array}$ & $\begin{array}{l}\text { Bersilaturrahmi kepada keluarga dan tetangga } \\
\text { serta bersahabat dengan orang-orang sholeh. }\end{array}$ \\
\hline 9. & Nilai Cinta Damai & Menghindari permusuhan dengan sesama muslim. \\
\hline 10. & Nilai Gemar Membaca & $\begin{array}{l}\text { Gemar membaca ayat-ayat Al-Qur'an dan } \\
\text { memahami isi kandungannya disertai dengan } \\
\text { melafadzkannya secara tartil. }\end{array}$ \\
\hline 11. & Nilai Peduli Sosial & Banyak menolong orang yang kesusahan. \\
\hline 12. & Nilai Tanggungjawab & Tanggungjawab kepada anak dan istri. \\
\hline
\end{tabular}

Nilai-nilai karakter yang terdapat oleh Pusat Kurikulum Depdiknas relevan dengan pendidikan karakter Imam Al-Haddad. Dengan ini mampu mengupayakan pembangunan karakter kepada peserta didik menuju perbaikan yang signifikan. Dengan karakter Islami dapat membangun generasi bangsa yang lebih bermanfaat untuk generasi selanjutnya. Berkaitan dengan karakter Islami tentunya berkaitan dengan hubungan vertikal dan horizontal yang mengedepankan akhlak mulia. Berkaitan dengan pendidikan karakter di Indonesia dapat saling melengkapi satu sama lain antar kedua konsep tersebut. Dengan tidak mengurangi substansinya namun memberi ruang untuk dapat berkembang beriringan.

\section{KESIMPULAN}

Berdasarkan penelitian yang telah disajikan sebelumnya, maka dapat disimpulkan bahwa:

Pertama, urgensi pendidikan karakter berpusat kepada diri sendiri bukan kepada masyarakat. Usaha yang terencana dalam pemikiran Imam Al-Haddad mewujudkan proses pembelajaran akhlak yang mulia untuk peserta didik berkembang, bukan hanya mengutamakan intelektualnya saja dan bukan juga untuk mendapatkan kedudukan ditengah-tengah masyarakat, tetapi juga memiliki akhlak mulia sehingga dapat terbentuk karakter peserta didik yang khas serta mempunyai tapak tilas akhlak mulia dan kemanfaatan ilmu dunia dan akhirat.

Kedua, karakter Islami yang mempunyai nilai-nilai karakter khas dan sudah meneladani akhlak-akhlak ulama terdahulu dapat menjadi perubahan perilaku lebih baik dalam jangka 
Scaffolding: Jurnal Pendidikan Islam dan Multikulturalisme

Vo. 3, No. 2, Juli-Desember 2021: 123-134

panjang. Perubahan perilaku dalam jangka panjang ini mendominasi peserta didik untuk dapat berperan aktif dalam karakter yang mendukungnya dalam akhlak mulia.

Ketiga, peserta didik tidak dapat dikatakan berilmu dan berakhlak mulia tanpa usaha awal dalam berakhlak mulia kepada Allah SWT sebagai sumber dari semua kebenaran. Semakin peserta didik berilmu dan berakhlak mulia akan semakin besar pengakuannya untuk mengutamakan kebesaran Allah SWT jauh diatas dirinya. Lalu, peserta didik yang dapat berakhlak mulia kepada Allah SWT akan mudah berakhlak mulia kepada semua ciptaan-Nya secara komprehensif.

Selanjutnya, penulis memberikan saran-saran diantara lain; Akhlak secara komprehensif dapat menjadi kurikulum di institusi pendidikan agama Islam, Bagi pendidik dapat pula menanamkan nilai-nilai pendidikan karakter secara komprehensif kepada peserta didik, Bagi peserta didik untuk dapat memperbaiki dan mengembangkan karakter secara komprehensif.

\section{BIBLIOGRAFI}

al-Badawi, Musthafa Hasan. (2016). Imam Al-Haddad: Tokoh Pembaharu Abad ke-12 H, diterjemahkan oleh Muhammad Shofi dari judul al-Imâm Al-Haddad Mujaddid al-Qarn ats-Thâni ‘Ashara al-Hijrŷ, Bantul: CV. Layar Creativa Mediatama.

al-Baihaqi, Abi Bakr Ahmad bin Husain. (1995). Shu'abu al-îmân, Beirut: Dar al-Kutub al'Ilmiyah.

Al-Haddad, Habib Abdullah bin Alwi. (2017). Langkah Praktis Mendekat kepada Allah SWT, di terjemahkan oleh Husin Nabil as-Saqqaf dari judul kitab Risâlâh Âdab Sulûk al-Murîd. Tangerang: Putera Bumi.

al-Mas'udi, Hasan. Taysirul Khollâq, Semarang: Maktabah al-Alawiyyah, t.th.

as-Suyuti, Jalaluddin dan Jalaluddin Muhammad bin Ahmad al-Mahally. (1923). Tafsir Jalalain, Singapura, Jeddah, Indonesia: Dar el-Arafah.

Baradja, Al-Ustadz Umar bin Achmad. (1993). Bimbingan Akhlak Bagi Putri-putri Anda 2, di terjemahkan oleh Abu Musthafa al-Halabi dari judul al-Akhlaq Lilbanât, Jakarta: Pustaka Amani.

Daud, Wan. (2003). Filsafat dan Praktik Pendidikan Islam Syed M. Naquib al-Attas, Bandung: Mizan Media Utama.

Depdiknas, Pusat Kurikulum. (2010). Bahan Pelatihan Penguatan Metodologi Pembelajaran Berdasarkan Nilai nilai Budaya untuk Membentuk Daya Saing dan Karakter Bangsa. Jakarta: Kemendiknas.

Hadi, Sutrisno. (1980). Metodologi Research Indek, Yogyakarta: Gajah Mada. 
Scaffolding: Jurnal Pendidikan Islam dan Multikulturalisme

Vo. 3, No. 2, Juli-Desember 2021: 123-134

Hendriana, Evinna Cinda dan Arnold Jacobus. "Implementasi Pendidikan Karakter di Sekolah melalui Keteladanan dan Pembiasaan," dalam Jurnal Pendidikan Dasar Indonesia, Vol. 1 No. 2 Tahun 2016.

Muslich, Masnur. 2012. Pendidikan Karakter: Menjawab Tantangan Krisis Multidimensial, Jakarta: Bumi Aksara.

Pasmadi, Achmad Kurniawan. “Konsep Rezeki Dalam Al-Qur'an,” dalam Jurnal Didaktika Islamika, Vol. 6 No.2 Tahun 2015.

Q-Annes, Bambang dan Adang Hambali. (2008). Pendidikan Karakter Berbasis Qur'ani, Bandung: Simbiosa Rekatama Media.

Rachman, Budhy Munawar dan Elza Peldi Taher. (2013). File CakNur Keislaman yang Hanif Buku ketiga J-0, Depok: Imania. 